\title{
So Far Away From One's Partner, Yet So Close to Romantic Alternatives: Avoidant Attachment, Interest in Alternatives, and Infidelity
}

\author{
C. Nathan DeWall \\ University of Kentucky
}

Erica B. Slotter

Northwestern University

Eli J. Finkel and Laura B. Luchies

Northwestern University

\author{
Nathaniel M. Lambert \\ The Florida State University
}

\author{
Richard S. Pond, Jr. and Timothy Deckman \\ University of Kentucky
}

Frank D. Fincham

The Florida State University

\begin{abstract}
Temptation pervades modern social life, including the temptation to engage in infidelity. The present investigation examines one factor that may put individuals at a greater risk of being unfaithful to their partner: dispositional avoidant attachment style. The authors hypothesize that avoidantly attached people may be less resistant to temptations for infidelity due to lower levels of commitment in romantic relationships. This hypothesis was confirmed in 8 studies. People with high, vs. low, levels of dispositional avoidant attachment had more permissive attitudes toward infidelity (Study 1), showed attentional bias toward attractive alternative partners (Study 2), expressed greater daily interest in meeting alternatives to their current relationship partner (Study 5), perceived alternatives to their current relationship partner more positively (Study 6), and engaged in more infidelity over time (Studies 3, 4, 7, and 8). This effect was mediated by lower levels of commitment (Studies 5-8). Thus, avoidant attachment predicted a broad spectrum of responses indicative of interest in alternatives and propensity to engage in infidelity, which were mediated by low levels of commitment.
\end{abstract}

Keywords: attachment style, infidelity, commitment, avoidance

Charles is married. His marriage has lasted several years, but he does not like to get close to his wife. He prefers to keep his distance. Charles does not understand why his friends and coworkers emphasize the importance of being committed to one's spouse. Commitment means intimacy, which is not something that Charles likes. He has expressed interest in alternatives to his spouse. $\mathrm{He}$ goes to clubs and parties to meet women, he tells others he is interested in women other than his spouse, and he likes to look at other women. On several occasions, Charles has engaged in actual infidelity.

This scenario illustrates a crucial, yet heretofore understudied, factor that gives rise to infidelity: the quality of an individual's

This article was published Online First October 3, 2011.

C. Nathan DeWall, Richard S. Pond, Jr., and Timothy Deckman, Department of Psychology, University of Kentucky; Nathaniel M. Lambert and Frank D. Fincham, Family Institute, The Florida State University; Erica B. Slotter, Eli J. Finkel, and Laura B. Luchies, Department of Psychology, Northwestern University.

This research was supported in part by National Science Foundation (NSF) Grants BCS-719780 (awarded to Eli J. Finkel) and BCS-1104118 (awarded to C. Nathan DeWall). The opinions and conclusions expressed herein are those of the authors and do not necessarily reflect the opinions of the NSF.

Correspondence concerning this article should be addressed to C. Nathan DeWall, 201 Kastle Hall, Department of Psychology, University of Kentucky, Lexington, KY 40506-0044. E-mail: nathan.dewall@uky.edu attachment bond. Even less work has investigated why certain attachment styles may be associated with expressing interest in alternatives to one's partner and engaging in infidelity.

Feeling close and committed to one's partner inhibits people from having interest in alternatives and engaging in infidelity (Drigotas, Safstrom, \& Gentilia, 1999; Rusbult, 1983). Because avoidantly attached people feel most comfortable with distance and detachment from their partner (Fraley \& Shaver, 2000; Mikulincer \& Shaver, 2003, 2007), they may have less of the commitment-inspired inhibition that normally prevents people from showing interest in alternatives and from engaging in infidelity. Therefore, avoidant attachment may relate to a broad pattern of responses indicative of interest in alternatives and propensity to engage in infidelity, associations that should be mediated by a lack of commitment to one's partner.

To test this hypothesis, we conducted eight studies. In each study, we measured individual differences in attachment style. Next, participants completed measures assessing their attitudes toward infidelity in their current relationship (Study 1), attentional bias toward alternatives (Study 2), interest in alternatives to their current relationship partner in their daily lives (Study 5) and in general (Study 6), and actual infidelity over time (Studies 3, 4, 7, and 8). In Studies 1-4, we tested whether avoidant attachment predicts more positive attitudes toward infidelity, more attentional bias toward relationship alternatives, and more infidelity. In Studies 5-8, we tested whether commitment mediates the relationship 
between avoidant attachment and interest in alternatives and propensity to engage in infidelity.

\section{Avoidant Attachment}

John Bowlby (1969/1982) characterized the attachment system as an inborn pattern of emotion, cognition, and behavior that organizes human activity across the life span. He also noted that people vary in terms of their dispositional tendencies toward avoidant attachment and anxious attachment (Bowlby, 1973; see also Brennan, Clark, \& Shaver, 1998). People who are high on the avoidance dimension tend to be uncomfortable with psychological closeness and intimacy, which leads them to cope with these feelings by behaviorally distancing themselves from their partner (Fraley \& Shaver, 2000; Mikulincer \& Shaver, 2003, 2007). Commitment would be one aspect of a relationship that could be negatively affected by such distancing, such that avoidantly attached people should remain relatively uncommitted to their relationship partner. In contrast, people who are high on the anxiety dimension tend to experience ambivalence, marked by a desire for closeness and a desire to avoid rejection (Campbell, Simpson, Boldry, \& Kashy, 2005). Whereas the avoidance dimension measures the behavioral strategies people use to regulate their attachment needs (Fraley \& Shaver, 2000), the anxiety dimension measures the affective and attributional processes involved in monitoring and appraising events for signs of threats to these needs.

Due to these characteristics, avoidant attachment is sometimes considered a deactivating attachment strategy, in which the primary functions of the attachment system, such as seeking physical or psychological closeness with an attachment figure, are suppressed (Mikulincer \& Shaver, 2003). A defining feature of avoidant attachment is that high levels of avoidance can "lead a person to be emotionally detached from a partner and to form superficial, cool relationships that lack the vitality and bonding power of affection and intimacy" (Mikulincer \& Shaver, 2003, p. 87). That is, avoidantly attached people should report low levels of commitment to their relationship partner, presumably out of their desire to maintain distance between them and their partner. This lower level of commitment should, in turn, predict greater interest in alternatives and possibly engaging in infidelity (Drigotas et al., 1999).

Because attachment orientation is quite stable over time (see Fraley, 2002, for meta-analytic evidence on this issue) and commitment fluctuates over time (Agnew, Van Lange, Rusbult, \& Langston, 1998; Sprecher, 1999), we did not attempt to model change in attachment orientation. In the unlikely event that we had detected change in attachment orientation over a small period of time, such change would have likely reflected little more than a one-time data hiccup instead of theoretically meaningful result. Although infidelity has a relatively low base rate of occurrence, it occurs at sufficiently high and variable rates to adequate model change over time (Drigotas et al., 1999). Therefore, there was theoretical and empirical precedent that lower levels of commitment may precede higher infidelity and that infidelity changes sufficiently over time to adequately model. The next section discusses prior work suggesting a relationship between avoidant attachment and infidelity, which is followed by a section that discusses why commitment should mediate this relationship.

\section{Why Might Avoidant Attachment Predict Infidelity?}

Indirect evidence supporting a possible relationship between avoidant attachment and infidelity comes from a variety of literatures. Avoidantly attached people tend to have an unrestricted or promiscuous sociosexual orientation (Brennan et al., 1998; Fraley, Davis, \& Shaver, 1998), which may reduce their propensity to engage sexual activities solely with their partner. Avoidant attachment is also associated with pursuing short-term sexual relationships (Schmitt, 2005), presumably because such relationships do not trigger the attachment-related discomfort they experience in long-term, committed relationships. In addition, avoidant attachment is associated with relatively weak motivations to engage in sexual behavior to experience emotional closeness, and is associated with assorted indicators of dishonest behavior (Davis, Shaver, \& Vernon, 2004; Ennis, Vrij, \& Chance, 2008; Gillath, Sesko, Shaver, \& Chun, 2010; Vrij, Floyd, \& Ennis, 2003).

To our knowledge, only two studies have investigated the relationship between attachment style and infidelity directly, and they have yielded mixed findings. In one study, participants who had an anxious attachment style, compared with a secure/avoidant attachment style reported having more affairs in the past year (Bogaert \& Sadava, 2002). This effect was especially true of women. Another study, in which a sample of participants were used who reported prior extradyadic involvement, showed that men (but not women) who were high in dispositional avoidant attachment reported the highest levels of extradyadic involvement over the past 2 years (Allen \& Baucom, 2004). Thus, attachment style can be used to predict infidelity, but it is unclear how anxious and avoidant dimensions relate to infidelity. Moreover, a mechanism was not identified in these prior studies underlying the relationship between attachment style and infidelity.

In the present studies, we sought to resolve the above inconsistency by examining how avoidant attachment and anxious attachment relate to attitudes toward cheating on a current relationship partner, attentional bias toward alternatives, interest in alternatives, and actual infidelity. However, we primarily emphasize avoidant, rather than anxious, attachment because discomfort with and attempts to reduce relational closeness constitute risk factors for increased interest in relationship alternatives and infidelity; these risk factors are characteristics of avoidant, not anxious, attachment. The next section fleshes out the conceptual framework underlying our prediction of commitment as a mediator of the relationship between avoidant attachment and infidelity.

\section{Why Might Commitment Mediate the Relationship Between Avoidant Attachment and Infidelity?}

We focus on commitment because prior evidence suggests that commitment is the most direct mediator when predicting behaviors that relate to the persistence of one's relationship and engagement of behaviors meant to strengthen one's relationship, accounting for variance beyond relationship satisfaction and investment in one's relationship (Johnson \& Rusbult, 1989; Rusbult, 1983; Van Lange et al., 1997). There are at least two reasons why commitment should mediate the relationship between avoidant attachment and greater interest in alternatives, more positive attitudes toward infidelity, and more infidelity.

First, commitment is tied to feeling dependent on one's partner, which refers to feeling that one needs one's relationship and that 
one's well-being is tied closely to involvement in the relationship (Kelley, 1979; Kelley \& Thibaut, 1978). According to interdependence theory (Rusbult \& Van Lange, 2003), dependence on one's partner increases to the extent that people feel satisfied with their relationship, feel that the quality of alternatives to their partner is low, and feel that they have invested a great deal of themselves in their relationship. The investment model asserts that commitment is a consequence of dependence, which normally prevents people from having interest in alternatives and engaging in behaviors that threaten the viability of one's relationship (Agnew et al., 1998; Johnson \& Rusbult, 1989; Rusbult, Van Lange, Wildschut, Yoveitch, \& Verette, 2000). Because avoidant attachment is associated with a lack of comfort being close to one's partner and with a strong desire to remain independent from one's partner, avoidantly attached people may have difficulty depending on their partner. Without strong feelings of dependence, avoidantly attached people may experience relatively low levels of commitment to their partner. As a result, avoidant attachment may relate to a heightened propensity to have interest in alternatives and to engage in behaviors that threaten the viability of one's relationship, such as infidelity.

Second, even among avoidantly attached people who experience dependence on their partner, experiencing commitment may disrupt their ability to experience detachment from their partner through deactivation strategies. Instead of viewing their identity as committed to their partner, avoidantly attached people may suppress these subjective feelings of commitment in order to maintain their sense of felt security. In the absence of a strong commitment to their partner, avoidantly attached people may be at risk for engaging in infidelity.

Therefore, we expected that high, versus low, levels of avoidant attachment would relate to lower levels of commitment, while controlling for levels of anxious attachment. Low, versus high, levels of commitment in turn would relate to more permissive attitudes toward infidelity, greater interest in alternatives, and more acts of infidelity over time.

\section{The Present Research}

In the present investigation, we tested the hypothesis that high, versus low, levels of avoidant attachment would relate to more positive attitudes toward cheating on a current relationship partner (Study 1), more attentional bias toward alternatives (Study 2), more daily interest in meeting alternatives (Study 5), more interest in alternatives to one's current relationship partner generally (Study 6), and more infidelity (Studies 3, 4, 7, and 8). In Studies $5-8$, we tested whether the relationship between avoidant attachment and interest in alternatives and infidelity was mediated by low levels of relationship commitment. We chose our sample sizes to provide sufficient power to detect a significant association between our predictor variables and our dependent variables based on previous social psychological research on infidelity (Drigotas et al., 1999).

\section{Study 1: Avoidant Attachment and Attitudes Toward Engaging in Infidelity}

Study 1 provided an initial test of our hypothesis that avoidant attachment would relate to more positive attitudes toward infidel- ity. We recruited participants who were involved in romantic relationships and measured their attitudes toward engaging in infidelity. We measured the relationship between avoidant attachment and specific attitudes toward cheating on their partner instead of general attitudes toward cheating because specific attitudes are reasonably good predictors of actual behavior (Ajzen \& Fishbein, 1977). The main prediction was that avoidant attachment would relate to more positive attitudes toward cheating on one's current relationship partner.

\section{Method}

Forty-two undergraduates ( 25 women) participated in this study in exchange for partial course credit. To participate in the study, participants must have been involved in a romantic relationship of at least 1 month in duration. Most participants described their relationship as committed $(76.7 \%$ committed, $16.3 \%$ dating casually, $4.7 \%$ married, $2.3 \%$ "other").

\section{Measures.}

Attachment style. Participants completed the Experiences in Close Relationships Scale to assess attachment style (ECR; Brennan et al., 1998). The avoidant attachment (Cronbach's $\alpha=.80$ ) and anxious attachment (Cronbach's $\alpha=.92$ ) items had strong internal reliability and were therefore averaged to create composite indices. One participant did not complete the avoidant attachment items, whereas two participants did not complete the anxious attachment items. These missing data are reflected in slightly different degrees of freedom in the Results section. The correlation between avoidant and anxious attachment was .47 $(p=.002)$.

Attitudes toward infidelity. Participants completed a fiveitem Attitude Toward Relationship Infidelity scale (ATRI) created for this experiment (i.e., "Cheating on my partner is morally wrong"; "If I could get away with it, I would cheat on my partner" [reverse scored]; "Being faithful to my romantic partner is important to me"; "Cheating on my romantic partner would not be a big deal" [reverse scored]; and "I would cheat on my romantic partner if I was given the opportunity" [reverse scored]; $1=$ Strongly Disagree, 5 = Strongly Agree). The internal reliability of the five items was strong (Cronbach's $\alpha=.78$ ), and therefore responses were summed to create a composite ATRI index. Lower scores indicated more positive attitudes toward relationship infidelity.

Procedure. Participants arrived at a large classroom in groups of two to six for a study ostensibly concerning the relationship between attention and relationships. Participants gave informed consent and then completed the ECR. After completing the ECR, participants completed the ATRI scale. Finally, participants received a debriefing.

\section{Results and Discussion}

We predicted that avoidantly attached people would report relatively positive attitudes toward cheating on their current partner. In this and all other studies in this investigation, we standardized all predictor variables to facilitate interpretation. Participant gender did not interact with attachment style in this or any of the other studies. Thus, we treated gender as a covariate in each study.

As expected, avoidant attachment related to more positive attitudes toward infidelity $(\beta=-0.37), t(40)=-2.53, p<.02$. Anxious attachment did not predict attitudes toward infidelity 
$(\beta=-0.11), t(39)=-0.68, p=.50$. Avoidant attachment remained a significant predictor of attitudes toward cheating on one's current partner after controlling for anxious attachment and participant gender $(\beta=-0.40), t(37)=-2.36, p=.02$.

Thus, Study 1 showed that avoidant, but not anxious, attachment predicted more positive attitudes toward infidelity. What these findings did not examine, however, is whether avoidant attachment relates to interest in alternatives at a basic, early stage level of social perception. To examine this possibility, we conducted Study 2.

\section{Study 2: Avoidant Attachment and Attentional Bias Toward Alternatives}

In Study 2, we sought to extend the results of Study 1 by showing that avoidant attachment relates to having an attentional bias toward alternatives to one's current relationship partner. Participants reported their attachment style and then completed a dot probe, reaction time task that assessed attentional bias to oppositesex targets that were prerated as either attractive or somewhat unattractive. We expected that avoidantly, but not anxiously, attached people would exhibit a greater attentional bias toward attractive members of the opposite sex, as those targets potentially represent appealing alternatives to one's current relationship partner.

\section{Method}

Participants. Two hundred five undergraduates (120 women) participated in this study in exchange for partial course credit. To participate in this study, participants must have been involved in a romantic relationship for at least 1 month. Average relationship length was 1.29 years $(S D=1.38)$.

\section{Measures.}

Attachment style. Participants completed the ECR (Brennan et al., 1998), used in Study 1. The internal reliability of the avoidant attachment (Cronbach's $\alpha=.84$ ) and anxious attachment (Cronbach's $\alpha=.93$ ) items was strong, and therefore responses were averaged to create composite indices. The correlation between avoidant and anxious attachment was .10 $(p=.17)$.

Procedure. Participants gave informed consent and then completed the ECR. After completing the ECR, participants were instructed that they would complete a visual cuing task. The task was a version of the visual dot probe procedure (e.g., DeWall, Maner, Deckman, \& Rouby, 2011). It assessed attentional engagement (how strongly a stimulus "captures" a person's attention) and attentional disengagement (how difficult it is for people to shift their attention away from a stimulus; Derryberry \& Reed, 1994). Each trial followed the same procedure. First, a fixation cross appeared in the center of the computer screen for 1,000 ms. Next, a target face appeared in one quadrant of the computer screen for $500 \mathrm{~ms}$. Once the target photo disappeared, a categorization object (circle or square) appeared in either the same location (attentional engagement trials) as the picture or in a different quadrant (attentional disengagement trials). The participants' job was to categorize the object as a circle or square by pressing the $E$ or $I$ key on the keyboard. The experimenter reminded participants that their responses would be timed, so they should respond as quickly and accurately as possible.
Participants completed a block of 10 practice trials, which was followed by two blocks of 44 main trials. Half of the main trials assessed attentional engagement, whereas the other half assessed attentional disengagement. In the practice trials, the target photos consisted of neutral, nonsocial objects (e.g., furniture). In the main trials, the target photos depicted novel opposite-sex targets. All photos were pretested by an independent group of undergraduate students $(n=32)$ for their level of physical attractiveness (from $1=$ very unattractive to $9=$ very attractive $)$. Half the opposite-sex targets were prerated as relatively attractive $(M=5.49, S D=$ 2.04), whereas the other half of the opposite-sex targets were prerated as being somewhat unattractive $(M=3.21, S D=1.83)$. After completing the dot probe task, participants received a debriefing.

The primary dependent measure in this study was the reaction time on attentional engagement and attentional disengagement trials. Averaging responses within each category yielded separate indices of attentional bias for attractive and less attractive opposite-sex targets. Incorrect responses were excluded from all analyses (less than 3\% of all trials). Following Robinson (2007), values greater than 2.5 standard deviations from the mean with cutoff scores that were 2.5 standard deviations from the mean were replaced.

Consistent with previous research (e.g., Maner, Gailliot, \& DeWall, 2007), sizable individual differences in overall speed of responding were observed. To ensure that the predicted effects were due to avoidant attachment and not to individual differences in how quickly participants responded, a standardized reaction time measure was used. Each participant's overall reaction time was subtracted from the average reaction time for each target category. This reaction time was then divided by the standard deviation of that participant's reaction times. The resultant variables represented attention bias for each target category that take into account individual differences in overall speed of responding.

Lower engagement scores reflected faster "capture" of visual attention, whereas higher disengagement scores reflected greater difficulty in disengaging one's attention away from the target photo. In each analysis, attentional engagement and disengagement was predicted for attractive alternatives while controlling for engagement and disengagement for less attractive alternatives because attention to attractive faces is most closely related to relationship outcomes (e.g., Maner et al., 2007).

\section{Results and Discussion}

We predicted that avoidant attachment would relate to greater attentional bias toward alternatives to one's current relationship partner. As expected, avoidant attachment was related to stronger attentional engagement to attractive opposite-sex targets $(\beta=$ $-0.18), t(197)=-2.60, p=.01$, indicating that avoidantly attached people were faster to have their attention "caught" by attractive opposite-sex targets (controlling for their attentional engagement to less attractive faces). Attachment anxiety was not related to attentional engagement toward attractive opposite-sex targets $(\beta=0.09), t(197)=1.29, p=.20$. Consistent with Study 1 , avoidant attachment remained a significant predictor of attentional engagement to attractive opposite-sex targets after controlling for attentional engagement to less attractive faces, anxious 
attachment, and participant gender $(\beta=-0.20), t(195)=-2.77$, $p=.006$.

Whereas avoidant attachment predicted faster engagement of attention to attractive opposite-sex targets, it did not influence how quickly it took participants to disengage their attention away from attractive opposite-sex targets (controlling for disengagement from less attractive faces) $(\beta=0.07), t(197)=0.91, p=.36$. Anxious attachment also bore no significant relation to attentional disengagement from attractive alternatives $(\beta=-0.10), t(197)=$ $-1.35, p=.18$. Avoidant attachment continued to have no reliable relationship to disengagement from attractive alternatives after controlling for disengagement from less attractive alternatives, anxious attachment, and participant gender $(\beta=0.08), t(195)=$ $0.86, p=.39$.

Study 2 offers additional evidence regarding the relationship between avoidant attachment and interest in alternatives. Whereas Study 1 showed that avoidant attachment related to more positive perceptions of infidelity on measures reliant upon explicit, higher order cognitive processes such as attitudes, Study 2 showed that avoidant attachment influenced automatic, early stage attentional processes presumed to underlie these downstream processes. Study 2 demonstrated that, as expected, avoidant attachment was related to biased attention to opposite-sex targets. Avoidantly attached people were quick to notice attractive alternatives in their environment.

Anxious attachment did not relate to attentional bias toward alternatives, which replicates the findings from Study 1 regarding the specificity of avoidant attachment in predicting permissive attitudes toward infidelity. The findings of Studies 1 and 2 converge on a portrait of avoidantly attached people as having positive attitudes toward engaging in infidelity and showing attentional biases toward potential alternatives to their partner. But these findings leave open the question as to whether avoidant attachment relates to actual infidelity. We therefore conducted two additional studies (Studies 3 and 4) to investigate this question.

\section{Study 3: Avoidant Attachment Predicts Higher Rates of Infidelity Over Time}

In Study 3, we sought to replicate and extend the results of Studies 1 and 2 by showing that avoidant attachment would predict higher rates of infidelity over time. Participants reported their attachment style and how much they had engaged in infidelity. Six weeks later, participants reported their level of infidelity again. We predicted that avoidant attachment would predict more infidelity on this second report, even after controlling for initial levels of infidelity, anxious attachment, and participant gender.

\section{Method}

Participants. Four hundred forty-two undergraduates began the study for extra credit and reported current involvement in an exclusive romantic relationship; however, 110 participants either broke up with their romantic partner or failed to complete all measures at Time 2. Three hundred thirty-two undergraduates (270 women) completed all measure at both time points. The relationship length of these individuals was as follows: $17.4 \% 3+$ years, $13.0 \% 2$ years, $20.9 \%$ 1-2 years, $12.8 \%$ 7-12 months, $8.7 \%$ 5-6 months, $13.7 \%$ 3-4 months, and $13.5 \%$ less than 2 months. All analyses were conducted with participants who persisted and completed all measures.

The individuals who dropped out were compared with those who completed the Time 2 measures and did not break up with their romantic partner. Participants who dropped out after Time 1 reported higher levels of avoidant attachment $(M=2.49, S D=$ 1.34) than did those who persisted and completed all measures $(M$ $=2.00, S D=1.08), F(1,440)=14.75, p<.001$. Furthermore, participants who dropped out after Time 1 reported higher levels of infidelity $(M=48.00, S D=19.28)$ than did those who persisted and completed all measures $(M=37.86, S D=20.48), F(1$, $440)=30.82, p<.001$. Because participants with higher levels of infidelity and avoidance attachment were least likely to be included in the sample at Time 2, this study may provide an especially conservative test of the hypothesis that avoidance predicts greater infidelity over time.

\section{Measures.}

Attachment style. Participants completed the 12-item short form of the Experiences in Close Relationships Scale to assess attachment style (ECR-S; Wei, Russell, Mallinckrodt, \& Vogel, 2007). The avoidant attachment (Cronbach's $\alpha=.76$ ) and anxious attachment (Cronbach's $\alpha=.84$ ) subscales had adequate reliability, and therefore responses were averaged to create composite scores. The correlation between avoidant and anxious attachment was .28 $(p<.01)$.

Infidelity. To measure infidelity, a validated nine-item Infidelity scale designed for young adult dating relationships that measures both emotional and physical infidelity (Drigotas et al., 1999) was used. This scale was chosen because of its sensitivity to the issue of social desirability. Specifically, the scale was developed to provide "a scale that could capture this behavior in such a manner that participants would be likely both to divulge information and to do so honestly" (Drigotas et al., 1999, p. 512).

Participants were instructed to think of a person to whom they were most attracted that was not their current relationship partner. Next, participants completed nine questions about their level of attraction (e.g., "How attractive did you find this person?"; from $0=$ Not at all attractive to $8=$ Extremely attractive), arousal (e.g., "How much arousal did you feel in their presence?"; from $0=\mathrm{No}$ arousal to $8=A$ great deal of arousal), emotional engagement (e.g., "How emotionally intimate were you with this person?"; from $0=$ Not at all emotionally intimate to $8=$ Extremely emotionally intimate), and physical involvement (e.g., "How physically intimate were you with this person?"; from $0=$ Not at all physically intimate to $8=$ Extremely physically intimate) with the alternative to their partner. The items had excellent internal reliability at both time points (Time 1: Cronbach's $\alpha=.95$; Time 2: Cronbach's $\alpha=.96$ ) and therefore were summed to create a composite infidelity index.

Procedure. Midway through the academic semester, participants completed demographic information, the ECR-S, and the infidelity measure. Six weeks later, they completed the infidelity measure again. After completing the second session, participants received a debriefing.

\section{Results and Discussion}

We predicted that avoidant attachment would predict higher rates of infidelity over time. To test this hypothesis, we predicted 
Time 2 infidelity from Time 1 infidelity, participant gender, anxious attachment, and avoidant attachment. Not surprisingly, Time 1 infidelity predicted Time 2 infidelity $(\beta=0.52), t(332)=10.98$, $p<.001$.

As predicted, avoidant attachment predicted increases in infidelity over time $(\beta=0.19), t(333)=3.55, p<.001$. Avoidant attachment continued to predict an increase in levels of infidelity over time even when controlling for Time 1 infidelity, participant gender, and anxious attachment $(\beta=0.10), t(329)=1.99, p<$ .05 . In contrast, anxious attachment did not predict increases in infidelity over time when controlling for Time 1 infidelity, participant gender, and anxious attachment $(\beta=0.06), t(329)=1.21$, $p=.23 .^{1}$

These findings dovetail nicely with the results from Studies 1 and 2. Avoidant attachment predicted engaging in more infidelity over the course of 6 weeks, controlling for initial levels of infidelity, participant gender, and anxious attachment. As in our previous studies, anxious attachment was not associated with infidelity. Thus, our findings indicate that avoidant attachment, but not anxious attachment, predicted more infidelity over time.

A limitation of this study is that an overall measure of infidelity was used that included both emotional and physical infidelity. In addition, the measure used in Study 3 may have left the presence of specific behaviors somewhat vague and open to interpretational biases. Is avoidant attachment predictive of specific behaviors involved in sexual infidelity, such as kissing, hugging/caressing, and having actual sexual intercourse? To determine the answer to this question, we conducted Study 4.

\section{Study 4: Avoidant Attachment and Sexual Infidelity Over Time}

We conducted Study 4 to extend the results of Study 3 by showing that avoidant attachment predicts more sexual infidelity behavior. Participants reported their attachment style and the amount of extradyadic sexual behaviors (e.g., kissing, hugging/ caressing, sexual intimacy without intercourse, sexual intercourse) in which they had engaged within the past 2 months. Twelve weeks later, participants reported how much they had engaged in the same extradyadic behaviors over the past 2 months. We predicted that avoidant attachment would relate to more sexual infidelity over time.

\section{Method}

Participants. Four hundred ninety-four undergraduates began the study for extra credit and reported current involvement in an exclusive romantic relationship; however, 191 participants either broke up with their romantic partner or failed to complete all measures at Time 2. Three hundred five undergraduates (254 women) completed all measures at both time points and did not break up with their relationship partner. For these individuals who were included in the analyses, relationship length was as follows: $19.9 \% 3+$ years, $13.1 \% 2$ years, $21.8 \% 1-2$ years, $13.6 \% 7-12$ months, 7.6\% 5-6 months, $11.7 \%$ 3-4 months, and $12.3 \%$ less than 2 months. All analyses were conducted with participants who completed all measures.

The individuals who dropped out were compared with those who completed the Time 2 measures. Participants who dropped out after Time 1 reported higher levels of infidelity $(M=1.23, S D=$ 1.29) than did those who persisted and completed all measures $(M=0.75, S D=1.09), F(1,492)=11.41, p=.001$. Furthermore, participants who dropped out after Time 1 reported higher levels of avoidant attachment $(M=13.17, S D=7.07)$ than those who persisted and completed all measures $(M=11.57, S D=$ $6.50), F(1,492)=6.70, p=.01$. These data indicate that participants who dropped out of the study were both higher in infidelity and avoidant attachment, which should weaken the strength of correlation between avoidant attachment and infidelity over time.

Measures.

Attachment style. To assess attachment style, participants again completed the ECR-S (Wei et al., 2007). Both the Avoidant (Cronbach's $\alpha=.84$ ) and Anxious Attachment (Cronbach's $\alpha=$ .76) subscales had adequate reliability, and therefore responses were averaged to create composite scores. The correlation between avoidant and anxious attachment was $.17(p<.01)$.

Sexual infidelity. At Time 1 and Time 2, participants completed a measure that assessed whether they engaged in four extradyadic sexual activities in the past 2 months with someone other than their specified romantic partner (kissing, hugging/ caressing, sexual intimacy without intercourse, and sexual intercourse) (Fincham, Lambert, \& Beach, 2010). Responses were no $=1$ or yes $=2$. Because the reliabilities at both time points were adequate (Time 1: Cronbach's $\alpha=.76$; Time 1: Cronbach's $\alpha=.64)$, responses were summed to create composite measures of sexual infidelity.

Procedure. Upon arriving at the laboratory, participants completed the ECR-S and the sexual infidelity measure. Twelve weeks later, participants returned to the laboratory and completed the sexual infidelity measure again. Afterward, they received a debriefing.

\section{Results and Discussion}

We predicted that avoidant attachment would predict more sexual infidelity over time. To test this hypothesis, we predicted Time 2 sexual infidelity from Time 1 sexual infidelity, participant gender, anxious attachment, and avoidant attachment. Sexual infidelity was consistent over time, with Time 1 sexual infidelity predicting Time 2 sexual infidelity $(\beta=0.40), t(302)=7.61, p<$ .001 .

As predicted, avoidant attachment predicted increases in infidelity over time $(\beta=0.17), t(303)=2.89, p<.001$. In contrast, anxious attachment did not predict later sexual infidelity $(\beta=$ $0.02), t(300)=0.44, p=.66$. As expected, higher avoidant attachment scores predicted more sexual infidelity over time, even when controlling for Time 1 infidelity, participant gender, and

\footnotetext{
${ }^{1}$ We also conducted exploratory analyses using the strictly emotional infidelity item and the strictly physical infidelity items. Although the direction of the effects was in the predicted direction, the significance tests fell short of acceptable levels of significance. Time 1 avoidant attachment marginally predicted more emotional infidelity at Time $2(\beta=0.09)$, $t(327)=1.65, p=.10$, controlling for Time 1 emotional infidelity, participant gender, avoidant attachment, and anxious attachment. Time 1 avoidant attachment did not predict more physical infidelity at Time 2 ( $\beta=$ $0.09), t(327)=1.12, p=.26$, controlling for Time 1 physical infidelity, participant gender, avoidant attachment, and anxious attachment.
} 
anxious attachment $(\beta=0.11), t(300)=2.14, p<.05$. We also ran separate analyses for each physical infidelity item, which we report in Table 1. As shown in that table, the relationship between avoidant attachment and infidelity was consistent across each type of behavior, though the strength of the relationship was highest for hugging, kissing, and sexual intimacy without intercourse.

Study 4 extends the results from the previous studies by showing that avoidant attachment, a disposition marked by feeling uncomfortable getting close to intimate relationship partners, was associated with engaging in more sexual infidelity over time. As in the previous studies, avoidant attachment robustly predicted more infidelity, remaining a significant predictor even after controlling for initial levels of sexual infidelity, participant gender, and attachment anxiety. Anxious attachment was unrelated to later sexual infidelity. Thus, Study 4 converges with our previous studies by showing that avoidant attachment was associated with more sexual infidelity. What these initial four studies did not show, however, was why avoidant attachment was linked to an attitudinal, attentional, and behavioral profile associated with greater interest in alternatives and more infidelity. In our last four studies, we sought to identify a mechanism underlying these effects.

\section{Study 5: Avoidant Attachment and Daily Desire to Meet Alternatives}

Having shown that avoidant attachment relates to a variety of indicators of interest in alternatives and infidelity, we sought to determine whether these responses were mediated by low levels of commitment. We used a daily diary format in Study 5, which allowed for a fine-grained analysis of the links between avoidant attachment, commitment, and interest in alternatives as they unfolded in people's daily lives over 5 weeks. We predicted that avoidant attachment would relate to lower levels of commitment, which would, in turn, relate to greater daily interest in meeting alternatives to one's partner.

\section{Method}

Participants. Fifty-one undergraduate heterosexual romantic couples participated in this study. To participate, participants must have been involved in a committed romantic relationship for at least 1 month. The average relationship length was 1.71 years $(S D=1.48)$. One member of each couple volunteered to take part in partial fulfillment of the requirements for an introductory psychology course, as well as monetary payment $(\$ 75)$, and the other

Table 1

Summary of Logistic Regression Analysis for Avoidant Attachment's Relationship to Individual Infidelity Items, Controlling for Each Variable at Time 1, Gender, and Anxious Attachment in Study 4

\begin{tabular}{lcccc}
\hline \multicolumn{1}{c}{ Variable } & $M$ & $S D$ & $(300, N=305)$ & $p$ \\
\hline Kissing & 1.08 & 0.27 & 7.48 & .01 \\
Hugging/caressing & 1.66 & 0.47 & 36.12 & .00 \\
Sexual intimacy & 1.05 & 0.21 & 3.31 & .07 \\
Intercourse & 1.03 & 0.18 & 2.12 & .15 \\
\hline
\end{tabular}

member participated in exchange for monetary payment $(\$ 75)$. One couple broke up before the end of the study; therefore, data from 50 couples (100 individuals) were left for final analysis.

\section{Measures.}

Attachment style. To assess attachment style, participants completed the ECR-S used in Study 3 (Wei et al., 2007). The avoidant attachment (Cronbach's $\alpha=.73$ ) and anxious attachment (Cronbach's $\alpha=.67$ ) subscales had adequate internal reliability, and therefore responses were averaged to create composite scores. In a multilevel regression analysis, avoidance and anxiety were positively related $(\beta=0.24, p=.02)$.

Commitment. Commitment was assessed with the seven-item (e.g., "I want our relationship to last a very long time"; "I am committed to maintaining my relationship with my partner") Commitment Level subscale of the Investment Model Scale (Rusbult, Martz, \& Agnew, 1998). The subscale showed adequate internal reliability (Cronbach's $\alpha=.88$ ), and therefore responses were averaged to create a composite measure of commitment.

Daily desire to meet alternatives. Daily desire to meet alternatives was assessed with two items that measured how much, over a 24-hr period, participants were interested in meeting members of the opposite sex. The instructions read "Relative to others days, over the last 24 hours, how much would you be interested in going out tonight with your friends to a. .." The first item was "dance club where you might meet men [women]," and the second item was "big party where you might meet men [women]." Responses were measured on a 9-point scale $(-4=$ Far less than usual, $0=$ Typical for me, and $+4=$ Far more than usual). These items were taken from prior work that examined factors that increase interest in alternatives (Haselton \& Gangestad, 2006). A composite measure of daily desire to meet alternatives was then computed by averaging responses across the two items (Cronbach's $\alpha=.91$ ).

Procedure. This study was part of a larger investigation regarding relationship well-being among college students. At an initial session, both members of each couple completed the ECR-S and the commitment measure. Participants then completed daily diary measures at the end of each day for a period of 5 weeks, which included the items assessing desire to meet alternatives. It took participants approximately $10 \mathrm{~min}$ to complete each nightly diary. After the 5-week diary portion of the study, each couple returned to the laboratory and received a debriefing.

\section{Results and Discussion}

Because the data are interval-contingent (i.e., daily measures nested within individual participants) and dyadic, their nested structure violates the assumption of independence in ordinary least squares regression. Therefore, we used multilevel modeling techniques to account for statistical nonindependence (e.g., Kenny, Kashy, \& Cook, 2006). All variables were standardized prior to analyses $(M=0, S D=1)$.

As predicted, avoidant attachment was associated with greater daily desire to meet alternatives $(\beta=0.11), t(1968)=5.34, p<$ .001. Anxious attachment was unrelated to daily desire to meet alternatives $(\beta=-0.004), t(1897)=-0.22, p=.83$. Avoidant attachment continued to predict greater daily interest in meeting alternatives after controlling for both anxious attachment and participant gender $(\beta=0.11), t(1879)=5.30, p<.001$. Thus, 
avoidant attachment was associated with higher levels of interest in meeting people of the opposite sex, regardless of anxious attachment.

Commitment as a mediator. Next, we investigated whether relationship commitment mediated the relationship between avoidant attachment and greater daily interest in meeting potential alternatives (controlling for anxious attachment and participant gender). For upper level mediation (independent variable and mediator at Level 2, dependent variable at Level 1), the recommended method for estimating the $95 \%$ confidence intervals of the indirect effect is to implement the empirical- $M$ test (Pituch \& Stapleton, 2008). As such, we used the computer program, PRODCLIN, to obtain the confidence interval of the indirect effect (MacKinnon, Fritz, Williams, \& Lockwood, 2007). As predicted, the indirect path through commitment was statistically significant, as the $95 \%$ confidence interval did not include zero [0.01, 0.06] (see Figure 1). Thus, avoidantly attached participants experienced lower levels of commitment to their partner, which in turn predicted their greater daily interest in meeting potential alternatives to their relationship partner.

Study 5 offers additional evidence that interest in alternatives is a core feature of avoidant attachment, which is mediated by low levels of commitment. In our next study, we sought to demonstrate that low levels of commitment again mediated the relationship between avoidant attachment and interest in alternatives. We also tested whether relationship satisfaction and closeness also mediated the relationship between avoidance and interest in alternatives.

\section{Study 6: Low Commitment Mediates the Link Between Avoidant Attachment and Interest in Alternatives}

In Study 6, we recruited participants who were involved in romantic relationships and measured their level of commitment to their relationship partner. Next, we measured how interested participants were in having a relationship with someone other than their current relationship partner. Some participants were involved in dating relationships, whereas others were married, which allowed us to examine whether the association of avoidant attachment with interest in alternatives would differ according to relationship type. We predicted that avoidant attachment would relate to greater interest in alternatives among both dating and married couples. In addition, we expected that the link between avoidant attachment and greater interest in alternatives would be mediated by low levels of relationship commitment. We also examined

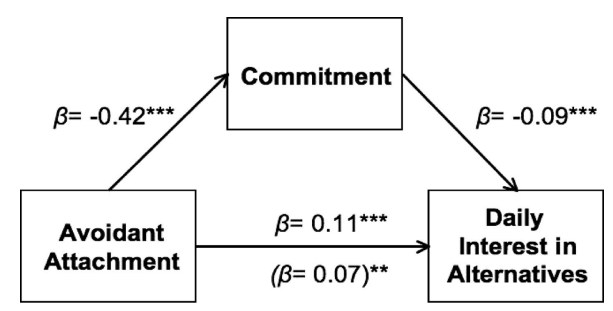

Figure 1. Daily commitment mediates the relationship between avoidant attachment and daily desire to meet alternatives (Study 5). ** $p<.01$. $^{* * *} p<.001$. whether relationship satisfaction and closeness mediated the relationship between avoidant attachment and interest in alternatives.

\section{Method}

Participants. One hundred ninety-five heterosexual couples participated in this study (390 individual participants). The couples came from two separate samples: one consisted of undergraduate students in dating relationships $(N=148)$; the other consisted of married adults recruited from the surrounding community $(N=$ 242). The participants in the dating sample had been romantically involved for an average of 1.41 years $(S D=1.14)$; the participants in the married sample had been romantically involved an average of 13.69 years $(S D=12.09)$.

\section{Measures.}

Attachment style. To assess attachment style, participants completed the ECR scale, used in Studies 1 and 2 (Brennan et al., 1998) scale. The avoidant attachment (Cronbach's $\alpha=.94$ ) and anxious attachment (Cronbach's $\alpha=.92$ ) items had excellent internal reliability, and therefore responses were averaged to create composite scores. In a multilevel regression analysis, avoidance and anxiety were positively related $(\beta=0.16, p=.002)$.

Commitment. Participants completed a seven-item measure of their commitment to their relationship partner from Rusbult et al. (1998; e.g., "I am committed to maintaining my relationship with my partner"; 1 = strongly disagree, 7 = strongly agree; Cronbach's $\alpha=.93$ ).

Interest in alternatives. Participants completed a five-item measure of their perceptions of the potential alternatives to their relationship from Rusbult et al. (1998; e.g., "The people other than my partner with whom I might become involved are very appealing"; 1 = strongly disagree, 7 = strongly agree ; Cronbach's $\alpha=$ $.83)$.

Relationship satisfaction. To assess relationship satisfaction, participants completed the five-item scale from Rusbult et al. (1998; e.g., "I feel satisfied with our relationship"; Cronbach's $\alpha=.91)$.

Closeness. To assess relationship closeness, participants completed the Inclusion of Other in Self measure (Aron, Aron, \& Smollan, 1992).

Procedure. The present study was part of a larger investigation of social psychological processes in romantic relationships. The larger investigation in which the present study was embedded consisted of multiple parts: an online survey, a laboratory-based experimental session, and six follow-up assessments. Relevant to the present study, all participants completed measures of attachment style, commitment, relationship satisfaction, closeness, and interest in alternatives to their current partner in a single session, during the online survey component of the larger study.

\section{Results and Discussion}

We predicted that avoidant attachment would relate to lower levels of commitment, which would, in turn, predict greater interest in alternatives. As our 390 participants were members of 195 couples, their data violate the independence assumption associated with ordinary least squares regression analyses. Thus, multilevel analyses were conducted that allowed us to account for the nonindependence in our data (e.g., Kenny et al., 2006). All variables were standardized prior to analyses $(M=0, S D=1)$. 
As expected, avoidant attachment was associated with greater interest in alternatives $(\beta=0.18), t(383)=3.61, p<.001$. Anxious attachment was unrelated to interest in alternatives $(\beta=$ $0.02), t(389)=0.38, p=.70$. Crucially, the association of avoidant attachment with interest in alternatives remained significant after simultaneously controlling for participants' anxious attachment, gender, and relationship type (dating vs. married) $(\beta=$ $0.15), t(379)=3.06 p=.002 .^{2}$ Thus, avoidant attachment was related to having greater interest in alternatives among people in both dating and married relationships.

Commitment as a mediator. To determine whether avoidantly attached participants' interest in alternatives was mediated by low levels of commitment to their relationship partner (controlling for anxious attachment, participant gender, and relationship type), we used the bootstrapping method developed by Preacher and Hayes (2008). A confidence interval for the size of the indirect path is generated, and if the values between the upper and lower confidence limit do not include zero, this indicates a statistically significant mediation effect. The indirect path through commitment was statistically significant, as indicated by finding that the 95\% confidence interval (bias corrected) for the indirect path, through the mediator, did not include zero [0.10, 0.23] (see Figure 2).

We also tested a multiple mediator model in which commitment, relationship satisfaction, and closeness were included as mediators of the relationship between avoidant attachment and greater interest in alternatives. Commitment continued to have a significant and the strongest indirect effect of all the mediators, with a confidence interval that did not include zero [0.09, 0.21]. Relationship satisfaction had a weaker, but still significant, indirect effect [0.001, 0.08], suggesting that it also acted as a mediator. The confidence interval for closeness included zero [-0.01, 0.02], indicating that it had a nonsignificant indirect effect.

Thus, Study 6 showed that interest in alternatives is a core feature of avoidant, but not anxious, attachment. It also showed that lower levels of commitment mediated the link between attachment avoidance and interest in alternatives. Relationship satisfaction also had an indirect effect, though it accounted for less variance in interest in alternatives compared with relationship commitment. Closeness did not act as a mediator.

Our final two studies had three aims. First, they sought to demonstrate that commitment reliably mediates the relationship between avoidant attachment and infidelity intentions and behavior. Second, they aimed to show that commitment precedes, rather than follows, infidelity. Third, they examined whether relationship satisfaction was a reliable additional mediator of the relationship

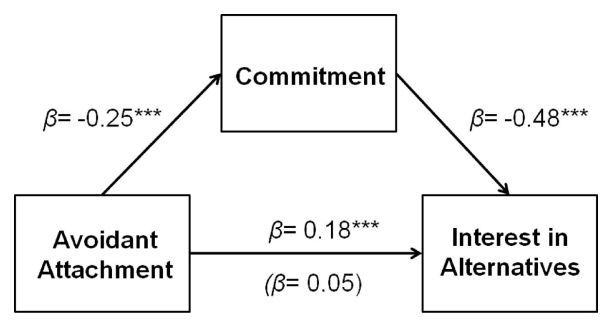

Figure 2. Commitment mediates the relationship between avoidant attachment and interest in alternatives (Study 6). ${ }^{* * *} p<.001$. between avoidant attachment and infidelity and whether closeness continued not to mediate.

\section{Study 7: Commitment Mediates the Relationship Between Avoidant Attachment and Infidelity Over Time}

In Study 7, we sought to replicate and extend the results of Studies 5 and 6 by showing that low levels of commitment mediate the relationship between avoidant attachment and infidelity. We hypothesized that avoidant attachment would predict more infidelity, even after controlling for initial infidelity, anxious attachment, and participant gender. We also predicted that later levels of commitment would mediate this relationship, controlling for initial levels of commitment. Finally, we tested whether commitment preceded, rather than followed, infidelity and whether relationship satisfaction and closeness also acted as mediators.

\section{Method}

Participants. Four hundred sixty undergraduates began the study for partial course credit and reported current involvement in an exclusive romantic relationship; however, 82 participants either broke up with their romantic partner or failed to complete all measures at Time 2. Three hundred seventy-eight undergraduates (320 women) completed all measures at both time points and did not break up with their romantic partner. For these individuals, relationship length was as folows: $20.3 \% 3+$ years, $15.6 \% 2$ years, $20.1 \%$ 1-2 years, $14.9 \%$ 7-12 months, 9.3\% 5-6 months, $9.7 \%$ 3-4 months, and $10.0 \%$ less than 2 months. All analyses were conducted with participants who persisted and completed all measures.

The individuals who dropped out were compared with those who completed the Time 2 measures. Participants who dropped out after Time 1 reported higher levels of avoidant attachment $(M=$ $2.58, S D=1.33)$ than did those who persisted and completed all measures $(M=2.11, S D=1.12), F(1,458)=11.27, p<.001$. In addition, participants who dropped out after Time 1 reported higher levels of infidelity $(M=4.44, S D=1.97)$ than did those who persisted and completed all measures $(M=3.76, S D=2.03)$, $F(1,458)=7.61, p<.01$. Given that participants highest in avoidant attachment and infidelity dropped out of the study, it should be more difficult to detect our hypothesized results.

Measures.

Attachment style. To assess attachment style, participants completed the ECR-S (Wei et al., 2007). The Avoidant Attachment (Cronbach's $\alpha=.77$ ) and Anxious attachment (Cronbach's $\alpha=$ .72) subscales had adequate internal reliability, and therefore responses were averaged to create composite scores. The correlation between avoidant and anxious attachment was .31 $(p<.01)$.

Commitment. Commitment was assessed using a short form of the Dedication subscale of Stanley and Markman's (1992) commitment measure. It comprised four items (e.g., "My relationship with my partner is more important to me than almost anything else in my life"; "I want this relationship to stay strong no matter what rough times we may encounter"; 1 = strongly disagree, $7=$

\footnotetext{
${ }^{2}$ Relationship type did not moderate these effects $(p=.15)$
} 
strongly agree). It showed acceptable internal reliability (Time 1: Cronbach's $\alpha=.80$; Time 2: Cronbach's $\alpha=.78$ ), and therefore responses were averaged to create a composite score.

Infidelity. To measure infidelity, the nine-item Infidelity scale from Study 3 was again used, which assessed emotional and physical infidelity (Drigotas et al., 1999). The items had excellent internal reliability at both time points (Time 1: Cronbach's $\alpha=$ .96; Time 2: Cronbach's $\alpha=.97$ ) and therefore were summed to create a composite infidelity index.

Relationship satisfaction. Relationship satisfaction was assessed using Funk and Rogge's (2007) four-item measure of relationship satisfaction. These items measured satisfaction with the participant's romantic partner or most important interpersonal relationship (e.g., "How rewarding is your relationship with your partner?" and "I have a warm and comfortable relationship with my partner"). The items were summed to create an index of relationship satisfaction (Time 1: Cronbach's $\alpha=.93$; Time 2 Cronbach's $\alpha=.91$ ).

Closeness. Closeness was assessed using two items "We have a lot of fun together" and "We regularly have great conversations where we just talk as good friends" (Rhoades, Stanley, \& Markman, 2009). These items were significantly correlated at Time 1 (.58) and at Time 2 (.63). The items were summed to create an index of closeness at each time point.

Procedure. Midway through the academic semester, participants completed demographic information, the ECR-S, the commitment measure, the relationship satisfaction measure, the closeness measure, and the infidelity measure. Six weeks later, they completed the commitment, relationship satisfaction, closeness, and infidelity measures again. After completing the second session, participants received a debriefing.

\section{Results and Discussion}

We predicted that avoidant attachment would predict more infidelity over time and that low levels of commitment would mediate this relationship. First, we examined the main effect of avoidant attachment on infidelity as we have in Studies 3 and 4. We predicted Time 2 infidelity from Time 1 infidelity, participant gender, anxious attachment, and avoidant attachment. As before, Time 1 infidelity predicted Time 2 infidelity $(\beta=0.54), t(375)=$ $12.47, p<.001$.

As predicted, avoidant attachment predicted increases in infidelity over time $(\beta=0.21), t(376)=4.12, p<.001$. Consistent with our prior studies, avoidant attachment continued to predict an increase in levels of infidelity over time even when controlling for Time 1 infidelity, participant gender, and anxious attachment $(\beta=$ $0.09), t(373)=2.02, p<.05$. In contrast, anxious attachment did not predict infidelity over time $(\beta=0.07), t(373)=1.54, p>.05$, controlling for Time 1 infidelity, participant gender, and anxious attachment. ${ }^{3}$

To test whether commitment preceded infidelity or whether infidelity preceded commitment, we ran two separate models. As expected, Time 1 higher commitment predicted less infidelity at Time $2(\beta=-0.11), t(372)=-2.19, p<.05$, controlling for Time 1 infidelity, participant gender, avoidant attachment, and anxious attachment. Conversely, Time 1 infidelity marginally predicted less commitment at Time $2(\beta=-0.07), t(372)=1.70$, $p=.09$, controlling for Time 1 commitment, participant gender, avoidant attachment, and anxious attachment.

Commitment as a mediator. First, we examined whether avoidant attachment predicted change over time in commitment by predicting Time 2 commitment from attachment avoidance (assessment at Time 1) and Time 1 commitment. Not surprisingly, Time 1 commitment predicted Time 2 commitment $(\beta=0.64)$, $t(376)=15.92, p<.001$. More importantly, avoidant attachment avoidance significantly predicted Time 2 commitment $(\beta=$ $-0.17), t(375)=-2.53, p=.01$, even after controlling for that robust stability coefficient. Relative to less avoidant people, more avoidant people became significantly less committed over time.

Next, to test whether commitment mediated the relationship between avoidant attachment and infidelity, we used the bootstrapping method (Preacher \& Hayes, 2008). As expected, the indirect path through commitment was statistically significant, as indicated by finding that the $95 \%$ confidence interval for the indirect path, through these mediators, did not include zero [0.06, 0.26] (see Figure 3). Thus, commitment significantly mediated the relationship between avoidant attachment and infidelity, even when controlling for initial commitment, infidelity, anxious attachment, and participant gender.

We reran the mediation analyses, this time as a multiple mediator model with relationship satisfaction and closeness included. The $95 \%$ confidence interval for the indirect path through commitment still did not include zero [0.02, 0.24], even when controlling for initial commitment, infidelity, anxious attachment, participant gender, and relationship satisfaction (at Time 1 and Time 2), and closeness (at Time 1 and Time 2). In contrast, the confidence interval for the indirect paths through relationship satisfaction $[-0.05,0.13]$ and closeness $[-0.02,0.06]$ included zero, using the same control variables. Thus, neither relationship satisfaction nor closeness mediated the relationship between avoidant attachment and later infidelity.

To determine the reliability of commitment as a mediator of infidelity, and whether it mediated the association of avoidant attachment with sexual infidelity specifically, we conducted a final study. We examined whether commitment mediated the link between avoidant attachment and sexual infidelity using the physical behaviors measure from Study 4 .

\section{Study 8: Commitment Mediates the Relationship Between Avoidant Attachment and Sexual Infidelity Over Time}

We conducted Study 8 to further verify that level of commitment mediates the relationship between avoidant attachment and more sexual infidelity. We predicted that avoidant attachment

\footnotetext{
${ }^{3}$ As in Study 3, we conducted exploratory analyses using the strictly emotional infidelity item and the strictly physical infidelity items. Although the direction of the effects was in the predicted direction, the significance tests fell short of acceptable levels. Time 1 avoidant attachment did not predict more emotional infidelity at Time $2(\beta=0.05)$, $t(369)=1.04, p=.30$, controlling for Time 1 emotional infidelity participant gender, avoidant attachment, and anxious attachment. Time 1 avoidant attachment marginally predicted more infidelity at Time 2 ( $\beta=$ $0.08), t(369)=1.68, p=.09$, controlling for Time 1 physical infidelity, participant gender, avoidant attachment, and anxious attachment.
} 


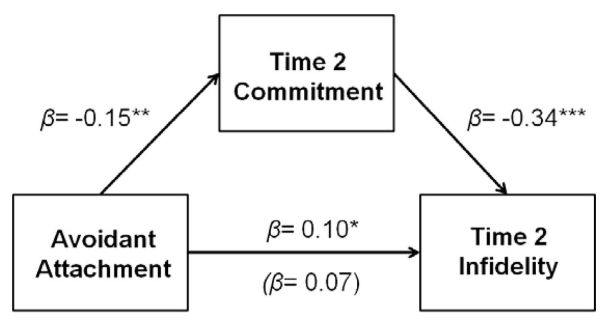

Figure 3. Commitment mediates the relationship between avoidant attachment and infidelity (Study 7). ${ }^{*} p<.05 .{ }^{* *} p<.01 .^{* * * *} p<.001$.

would relate to more sexual infidelity and that this would be mediated by level of commitment to the primary partner. As in Study 7, we also examined whether commitment preceded or followed infidelity and whether relationship satisfaction and closeness acted as additional mediators.

\section{Method}

Participants. Four hundred sixty-two undergraduates began the study for extra credit and reported current involvement in an exclusive romantic relationship; however, 133 participants either broke up with their romantic partner or failed to complete all measures at Time 2. Three hundred twenty-nine undergraduates (271 women) completed all measures at both time points and did not break up with their romantic partner. For these individuals, relationship length was as followd: $20.1 \% 3+$ years, $14.6 \% 2$ years, 20.3\% 1-2 years, 15.9\% 7-12 months, 10.3\% 5-6 months, $8.7 \%$ 3-4 months, and $10.0 \%$ less than 2 months. All analyses were conducted with participants who persisted in completing all measures.

The individuals who dropped out were compared with those who completed the Time 2 measures and did not break up with their romantic partner. Participants who dropped out after Time 1 reported higher levels of avoidant attachment $(M=2.39, S D=$ 1.31) than those who persisted and completed all measures $(M=$ $1.90, S D=1.08), F(1,460)=16.66, p<.001$. Participants who dropped out after Time 1 also reported higher levels of infidelity $(M=0.95, S D=1.47)$ than those who persisted and completed all measures $(M=0.55, S D=1.12), F(1,460)=10.36, p<.001$.

\section{Measures.}

Attachment style. To assess attachment style, the ECR-S (Wei et al., 2007) was again used. Both the Avoidant Attachment (Cronbach's $\alpha=.84$ ) and Anxious Attachment (Cronbach's $\alpha=$ .73) subscales had adequate reliability, and therefore responses were averaged to create composite scores. The correlation between avoidant and anxious attachment was $.15(p<.01)$.

Sexual infidelity. As in Study 4, participants completed a measure that assessed whether they engaged in four extradyadic activities in the past 2 months with someone other than their specified romantic partner (kissing, hugging/caressing, sexual intimacy without intercourse, and sexual intercourse) at Time 1 and Time 2 (Time 1: Cronbach's $\alpha=.85$; Time 2: Cronbach's $\alpha=$ .76) (Fincham et al., 2010).

Commitment. Commitment was again assessed using a short form of the four-item Dedication subscale of Stanley and Markman's (1992) commitment measure. It showed acceptable internal consistency (Time 1: Cronbach's $\alpha=.78$; Time 2: Cronbach's $\alpha=.76$ ), and therefore responses were averaged to create a composite score.

Relationship satisfaction. Relationship satisfaction was again assessed using Funk and Rogge's (2007) four-item measure of relationship satisfaction (Time $1 \alpha=.91$; Time $2 \alpha=.89$ ).

Closeness. Closeness was assessed using the same two items from Study 7. These items were significantly correlated at Time 1 (.48) and at Time 2 (.66). The items were summed to create an index of closeness at each time point.

Procedure. Upon arriving at the laboratory, participants completed demographic information, the ECR-S, the commitment measure, the relationship satisfaction measure, the closeness measure, and the sexual infidelity measure. Twelve weeks later, participants returned to the laboratory and completed the relationship satisfaction, closeness, and sexual infidelity measures again. Afterward, participants received a debriefing.

\section{Results and Discussion}

We first tested the main effect of avoidant attachment on later infidelity. We predicted Time 2 sexual infidelity from Time 1 sexual infidelity, participant gender, anxious attachment, and avoidant attachment. As in our previous studies, sexual infidelity was consistent over time, with Time 1 sexual infidelity predicting Time 2 sexual infidelity $(\beta=0.39), t(326)=7.60, p<.001$.

As predicted, avoidant attachment predicted increases in infidelity over time $(\beta=0.26), t(327)=4.91, p<.001$. Consistent with our prior studies, avoidant attachment continued to predict an increase in levels of infidelity over time even when controlling for Time 1 infidelity, participant gender, and anxious attachment $(\beta=$ $0.16), t(324)=3.14, p<.01$. Anxious attachment did not predict changes in sexual infidelity $(\beta=0.00), t(324)=0.05, p=.96$, controlling for Time 1 infidelity, participant gender, and anxious attachment. We also ran separate analyses for each physical infidelity item, which we report in Table 2 . As shown in that table, the relationship between avoidant attachment and infidelity was reliable across each type of behavior, though the strength of the relationship was highest for kissing, sexual intercourse, and sexual intimacy without intercourse.

As in Study 7, we tested whether commitment preceded infidelity or whether infidelity preceded commitment by running two separate models. As expected, Time 1 commitment predicted somewhat more infidelity at Time $2(\beta=0.11), t(323)=1.79$, $p=.08$, controlling for Time 1 infidelity, participant gender,

Table 2

Summary of Logistic Regression Analyses for Avoidant Attachment's Relationship to Individual Infidelity Items, Controlling for Each Variable at Time 1, Gender, and Anxious Attachment in Study 8

\begin{tabular}{lcccc}
\hline \multicolumn{1}{c}{ Variable } & $M$ & $S D$ & $(323, N=329)$ & $p$ \\
\hline Kissing & 1.14 & 0.34 & 24.33 & .00 \\
Hugging/caressing & 1.34 & 0.48 & 8.42 & .00 \\
Sexual intimacy & 1.06 & 0.24 & 12.85 & .00 \\
Intercourse & 1.07 & 0.25 & 15.84 & .00 \\
\hline
\end{tabular}


avoidant attachment, and anxious attachment. Conversely, Time 1 infidelity bore no relations to commitment at Time $2(\beta=0.00)$, $t(321)=-0.07, p=.95$, controlling for Time 1 commitment, participant gender, avoidant attachment, and anxious attachment. Thus, commitment preceded infidelity. These findings provide stronger evidence that commitment preceded infidelity than infidelity preceding commitment.

Commitment as a mediator. First, as in Study 7, we examined whether avoidant attachment predicted change over time in commitment by predicting Time 2 commitment from attachment avoidance (assessment at Time 1) and Time 1 commitment. Not surprisingly, Time 1 commitment predicted Time 2 commitment $(\beta=0.69), t(325)=15.32, p<.001$. More importantly, avoidant attachment avoidance significantly predicted Time 2 commitment $(\beta=-0.12), t(324)=-2.33, p<$ .05 , even after controlling for that robust stability coefficient. Relative to less avoidant people, more avoidant people became significantly less committed over time.

Next, to test whether commitment functioned as a mediator between avoidant attachment and infidelity, we again used bootstrapping (Preacher \& Hayes, 2008). The indirect path through commitment was statistically significant, as the confidence interval did not include zero [0.02, 0.14] (see Figure 4), indicating that commitment significantly mediated the proposed relationship, even when controlling for initial commitment, infidelity, and gender.

We again reran the mediation analyses, this time as a multiple mediator model with relationship satisfaction and closeness included. The confidence interval for the indirect path through commitment still did not include zero [ $-0.15,-0.01]$, even when controlling for initial commitment, infidelity, anxious attachment, participant gender, and relationship satisfaction (at Time 1 and Time 2), and closeness (at Time 1 and Time 2). In contrast, the confidence interval for the indirect paths through relationship satisfaction [ $-0.07,0.01]$ and closeness [ $-0.03,0.03]$ included zero, which included the same control variables. Thus, as in Study 7, neither relationship satisfaction nor closeness mediated the relationship between avoidant attachment and sexual infidelity over time.

Study 8 once again replicated the main effect of avoidant attachment on infidelity demonstrated in Studies 1-7. Study 8 provided additional evidence showing that level of commitment to the primary partner mediated the relationship between avoidant attachment and sexual infidelity. Avoidantly attached individuals were less inclined to commit to their romantic partner over time, which had direct implications for them choosing to engage in extradyadic sexual behavior.

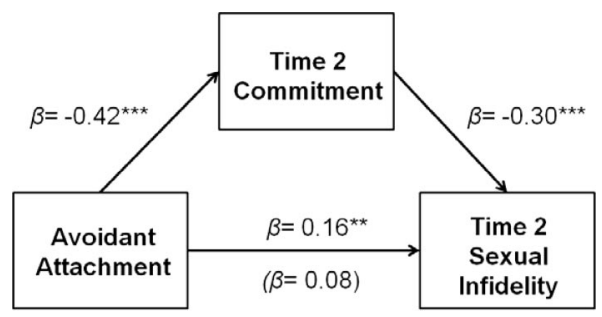

Figure 4. Commitment mediates the relationship between avoidant attachment and infidelity (Study 8). ${ }^{* *} p<.01 .^{* * *} p<.001$.

\section{General Discussion}

People in exclusive romantic relationships, by definition, have one partner. Yet, alternatives to one's relationship partner are ubiquitous. People in relationships often express little to no interest in those alternatives and derogate those alternatives (Johnson \& Rusbult, 1989). Psychological commitment to one's partner helps make this resistance possible. Therefore, people with a dispositionally avoidant attachment style, who feel uncomfortable having closeness and commitment in their relationships, should be especially likely to express interest in alternatives and to engage in infidelity.

Eight studies, using multiple measures and methods, consistently supported this hypothesis. The first four studies showed that avoidant attachment was related to more positive attitudes toward cheating on a current relationship partner, having an attentional bias toward alternatives, and engaging in more infidelity. In Study 1, avoidant attachment predicted more positive attitudes toward engaging in acts of infidelity. In Study 2, avoidant attachment was related to having an attentional bias to alternatives, with greater attentional engagement to attractive alternatives. In Study 3, avoidant attachment predicted more emotional and physical infidelity over time. In Study 4, avoidant attachment was related to engaging in more sexual infidelity over time. Thus, avoidantly attached people showed an attitudinal, attentional, and behavioral profile reflecting greater interest in alternatives and a propensity to engage in infidelity.

The final four studies showed that lower levels of commitment mediated the relationship between avoidant attachment and interest in alternatives and infidelity. In Study 5, avoidant attachment predicted greater daily interest in meeting potential alternatives, which was mediated by low levels of commitment. In Study 6, avoidant attachment predicted greater interest in alternatives among dating and married couples, which was mediated by low levels of commitment. In Study 7, avoidant attachment predicted more emotional and physical infidelity, which was mediated by low levels of commitment. In Study 8, avoidant attachment predicted more sexual infidelity, which was mediated by low levels of commitment. Neither relationship satisfaction nor closeness reliably mediated the relationship between avoidant attachment and infidelity across Studies 6-8. In addition, commitment preceded, rather than followed, infidelity, providing additional support for our hypothesized model. Thus, avoidant attachment was consistently related to low levels of commitment to one's romantic relationship partner, which, in turn, predicted greater interest in alternatives to one's partner and more infidelity.

Anxious attachment, in contrast, bore no relation to any of these outcomes. The implication is that people who crave closeness and connection with a current relationship partner do not express heightened interest in alternatives, report positive attitudes toward cheating on their partner, or show a heightened propensity to engage in extradyadic behaviors, as doing so could threaten the possibility of having a close and committed bond with their partner.

More broadly, the present findings speak to the power of commitment in shaping desires, attitudes, and behaviors linked to relationship well-being. People override their interest in alternatives and urge to engage in infidelity because doing so is rewarded with a relationship marked by closeness and commitment. Given 
the ubiquity of alternatives to one's relationship partner, having a strong sense of commitment with one's partner is a strong inhibitory force in preventing people from engaging in behaviors that could threaten their ability to have a close and lasting bond with their partner.

When people have deficits in their feelings of closeness with others, they are less willing to override their impulses to engage in behaviors that bring short-term pleasure but may incur long-term costs (e.g., Baumeister, DeWall, Ciarocco, \& Twenge, 2005; DeWall, Baumeister, \& Vohs, 2008). The results of our studies demonstrate that commitment is an interpersonal force that assists individuals in overriding their desire for alternatives to their current relationship partner. Moreover, among people who desire relationships marked by psychological distance and detachment, engaging in infidelity may offer them a temporary reprieve from their exclusive relationship through an interpersonal encounter that is largely devoid of expectations for commitment. To be sure, our findings do not suggest that avoidantly attached people are at risk for engaging in infidelity out of a desire to harm their partner. Instead, avoidantly attached people appear deficient in an inhibitory force that normally keeps such interest and urges at bay, namely the desire for strong interpersonal commitment, which in turn predicts their greater interest in alternatives and propensity to engage in infidelity.

\section{Limitations and Future Directions}

Our findings provided consistent evidence regarding our hypothesized relationships between avoidant attachment and interest in alternatives, attitudes toward infidelity, engaging in infidelity behaviors, and commitment. Despite the consistency of these findings, there are some limitations that deserve consideration. First, we did not measure how satisfied participants in Studies 3, 4, 7, and 8 were with the extradyadic behaviors in which they engaged. Although avoidant attachment predicted more infidelity, it is possible that avoidantly attached people experienced little or no enjoyment from such behaviors. If true, then this would weaken the argument that avoidantly attached people engage in infidelity because such encounters match their desire for relationships marked by psychological distance and detachment (Fraley \& Shaver, 2000).

This possibility is unlikely for two reasons. First, people may experience dissatisfaction with their extradyadic behaviors because such affairs are characterized by relatively low levels of psychological closeness and commitment, but this is precisely the type of encounter that avoidantly attached people find appealing. Second, participants showed a consistent propensity to engage in infidelity over time. It is unlikely that people would repeatedly engage in behavior in which they received little positive reinforcement. Therefore, there is theoretical and empirical precedent for explaining avoidantly attached people's greater infidelity as due in part to their relatively low levels of commitment.

A second limitation, which may provide a springboard for future research, is that our studies focused on how avoidant attachment relates to interest in alternatives and infidelity within established relationships. It is an open question as to how avoidant attachment relates to interest in alternatives and desire for extradyadic behaviors across the development of a romantic relationship. Do avoidantly attached people begin their relationships with an open stance toward engaging in infidelity? Or does such a stance develop primarily at later stages of one's relationship, in which avoidantly attached people grow uncomfortable with increased overtures to establish psychological closeness and commitment? Research on relationship initiation has grown considerably in recent years, with the advent of novel methods to investigate these processes such as speed-dating (Finkel, Eastwick, \& Matthews, 2007). Exploring how avoidant attachment relates to the development of interest in alternatives and interest in infidelity across the development of a relationship may add to a growing interest in understanding recently initiated romantic relationships.

A related limitation is that we focused on dispositional attachment style instead of exploring whether fleeting feelings of avoidance would produce similar effects on interest in alternatives and infidelity. To be sure, attachment representations are context sensitive. Indeed, recent work has shown that manipulating avoidant attachment produces effects that are theoretically consistent with those found among dispositionally avoidantly attached people (Beck \& Clark, 2009). Future work can explore how temporary feelings of avoidance may give rise to thoughts, attitudes, and behaviors related to infidelity.

\section{Concluding Remarks}

People exist in a social environment filled with temptation, including people who represent potential alternatives to one's relationship partner. Normally, desires for closeness, intimacy, and commitment diminish interest in alternatives and the propensity to engage in infidelity. Our findings suggest that chronic discomfort with closeness and intimacy, as indicated by relatively high levels of an avoidant attachment style, has direct consequences for how interested people are in alternatives to their relationship partner, their attitudes toward cheating on their partner, how committed they are, and hence how much they engage in infidelity. By keeping psychological distance from one's partner and remaining relatively uncommitted, avoidantly attached people maintain their desire for independence and self-reliance. But remaining uncommitted gives rise to behaviors that undermine relationship wellbeing and potentially result in relationship dissolution.

\section{References}

Agnew, C. R., Van Lange, P. A. M., Rusbult, C. E., \& Langston, C. A. (1998). Cognitive interdependence: Commitment and the mental representation of close relationships. Journal of Personality and Social Psychology, 74, 939-954. doi:10.1037/0022-3514.74.4.939

Ajzen, I., \& Fishbein, M. (1977). Attitude-behavior relations: A theoretical analysis and review of empirical research. Psychological Bulletin, 84, 888-918. doi:10.1037/0033-2909.84.5.888

Allen, E. S., \& Baucom, D. H. (2004). Adult attachment and patterns of extradyadic involvement. Family Process, 43, 467-488. doi:10.1111/ j.1545-5300.2004.00035.x

Aron, A., Aron, E., \& Smollan, D. (1992). Inclusion of Other in the Self scale and the structure of interpersonal closeness. Journal of Personality and Social Psychology, 63, 596-612. doi:10.1037/0022-3514.63.4.596

Baumeister, R. F., DeWall, C. N., Ciarocco, N. J., \& Twenge, J. M. (2005). Social exclusion impairs self-regulation. Journal of Personality and Social Psychology, 88, 589-604. doi:10.1037/0022-3514.88.4.589

Beck, L. A., \& Clark, M. S. (2009). Choosing to enter or avoid diagnostic social situations. Psychological Science, 20, 1175-1181. doi:10.1111/ j.1467-9280.2009.02420.x 
Bogaert, A. F., \& Sadava, S. (2002). Adult attachment and sexual behavior. Personal Relationships, 9, 191-204. doi:10.1111/1475-6811.00012

Bowlby, J. (1973). Attachment and loss: Vol. 2. Separation. New York, NY: Basic Books.

Bowlby, J. (1982). Attachment and loss: Vol. 1. Attachment. New York, NY: Basic Books. (Original work published 1969)

Brennan, K. A., Clark, C. L., \& Shaver, P. R. (1998). Self-report measurement of adult attachment: An integrative overview. In J. A. Simpson \& W. S. Rholes (Ed.), Attachment theory and close relationships (pp. 46-76). New York, NY: Guilford Press.

Campbell, L., Simpson, J. A., Boldry, J., \& Kashy, D. A. (2005). Perceptions of conflict and support in romantic relationships: The role of attachment anxiety. Journal of Personality and Social Psychology, 88, 510-531. doi:10.1037/0022-3514.88.3.510

Davis, D., Shaver, P. R., \& Vernon, M. L. (2004). Attachment style and subjective motivations for sex. Personality and Social Psychology Bulletin, 30, 1076-1090. doi:10.1177/0146167204264794

Derryberry, D., \& Reed, M. A. (1994). Temperament and attention: Orienting toward and away from positive and negative signals. Journal of Personality and Social Psychology, 66, 1128-1139. doi:10.1037/00223514.66.6.1128

DeWall, C. N., Baumeister, R. F., \& Vohs, K. D. (2008). Satiated with belonginess? Effects of acceptance, rejection, and task framing on selfregulatory performance. Journal of Personality and Social Psychology, 95, 1367-1382. doi:10.1037/a0012632

DeWall, C. N., Maner, J. K., Deckman, T., \& Rouby, D. A. (2011). Forbidden fruit: Inattention to attractive alternatives provokes implicit relationship reactance. Journal of Personality and Social Psychology, 100, 621-629.

Drigotas, S. M., Safstrom, C. A., \& Gentilia, T. (1999). An investment model prediction of dating infidelity. Journal of Personality and Social Psychology, 77, 509-524. doi:10.1037/0022-3514.77.3.509

Ennis, E., Vrij, A., \& Chance, C. (2008). Individual differences and lying in everyday life. Journal of Social and Personal Relationships, 25, 105-118. doi:10.1177/0265407507086808

Fincham, F. D., Lambert, N. M., \& Beach, S. R. H. (2010). Faith and unfaithfulness: Can praying for your partner reduce infidelity? Journal of Personality and Social Psychology, 99, 649-659. doi:10.1037/ a0019628

Finkel, E. J., Eastwick, P. W., \& Matthews, J. (2007). Speed-dating as an invaluable tool for studying romantic attraction: A methodological primer. Personal Relationships, 14, 144-166. doi:10.1111/j.14756811.2006.00146.x

Fraley, R. C. (2002). Attachment stability from infancy to adulthood: Meta-analysis and dynamic modeling of developmental mechanisms. Personality and Social Psychology Review, 6, 123-151. doi:10.1207/ S15327957PSPR0602 03

Fraley, R. C., Davis, K. E., \& Shaver, P. R. (1998). Dismissing-avoidance and the defensive organization of emotion, cognition, and behavior. In J. Simpson \& W. S. Rholes (Eds.), Attachment theory and close relationships (pp. 249-280). York, NY: Guilford Press.

Fraley, R. C., \& Shaver, P. R. (2000). Adult romantic attachment: Theoretical developments, emerging controversies, and unanswered questions. Review of General Psychology, 4, 132-154. doi:10.1037/10892680.4.2.132

Funk, J. L., \& Rogge, R. D. (2007). Testing the ruler with item response theory: Increasing precision of measurement for relationship satisfaction with the Couples Satisfaction Index. Journal of Family Psychology, 21, 572-583. doi:10.1037/0893-3200.21.4.572

Gillath, O., Sesko, A. K., Shaver, P. R., \& Chun, S. D. (2010). Attachment, authenticity, and honesty: Dispositional and experimentally induced security can reduce self- and other-deception. Journal of Personality and Social Psychology, 98, 841-855. doi:10.1037/a0019206

Haselton, M. G., \& Gangestad, S. W. (2006). Conditional expression of women's desires and men's mate guarding across the ovulatory cycle. Hormones and Behavior, 49, 509-518. doi:10.1016/j.yhbeh.2005.10.006

Johnson, D. J., \& Rusbult, C. E. (1989). Resisting temptation: Devaluation of alternative partners as a means of maintaining commitment in close relationships. Journal of Personality and Social Psychology, 57, 967980. doi:10.1037/0022-3514.57.6.967

Kelley, H. H. (1979). Personal relationships: Their structure and processes. Hillsdale, NJ: Erlbaum.

Kelley, H. H., \& Thibaut, J. W. (1978). Interpersonal relations: A theory of interdependence. New York, NY: Wiley.

Kenny, D. A., Kashy, D. A., \& Cook, W. L. (2006). Dyadic data analysis. New York, NY: Guildford Press.

MacKinnon, D. P., Fritz, M. S., Williams, J., \& Lockwood, C. M. (2007), Distribution of the product confidence limits for the indirect effect: Program PRODCLIN. Behavior Research Methods, 39, 384-389. doi: 10.3758/BF03193007

Maner, J. K., Gailliot, M. T., \& DeWall, C. N. (2007). Adaptive attentional attunement: Evidence for mating-related perceptual bias. Evolution and Human Behavior, 28, 28-36. doi:10.1016/j.evolhumbehav.2006.05.006

Mikulincer, M., \& Shaver, P. R. (2003). The attachment behavioral system in adulthood: Activation, psychodynamics, and interpersonal processes. In M. P. Zanna (Ed.), Advances in experimental social psychology (Vol. 35, pp. 53-152). New York, NY: Academic Press.

Mikulincer, M., \& Shaver, P. R. (2007). Attachment in adulthood: Structure, dynamics, and change. New York, NY: Guilford Press.

Pituch, K. A., \& Stapleton, L. M. (2008). The performance of methods to test upper-level mediation in the presence of nonnormal data. Multivariate Behavioral Research, 43, 237-267. doi:10.1080/ 00273170802034844

Preacher, K. J., \& Hayes, A. F. (2008). Asymptotic and resampling strategies for assessing and comparing indirect effects in multiple mediator models. Behavior Research Methods, 40, 879-891. doi:10.3758/ BRM.40.3.879

Rhoades, G. K., Stanley, S. M., \& Markman, H. J. (2009). The preengagement cohabitation effect: A replication and extension of previous findings. Journal of Family Psychology, 23, 107-111. doi:10.1037/ a0014358

Robinson, M. D. (2007). Lives lived in milliseconds: Using cognitive methods in personality research. In R. W. Robins, C. R. Fraley, \& R. F. Krueger (Eds.) Handbook of research methods in personality psychology (pp. 345-359). New York, NY: Guilford Press.

Rusbult, C. E. (1983). A longitudinal test of the investment model: The development (and deterioration) of satisfaction and commitment in heterosexual involvements. Journal of Personality and Social Psychology, 45, 101-117. doi:10.1037/0022-3514.45.1.101

Rusbult, C. E., Martz, J. M., \& Agnew, C. R. (1998). The Investment Model Scale: Measuring commitment level, satisfaction level, quality of alternatives, and investment size. Personal Relationships, 5, 357-387. doi:10.1111/j.1475-6811.1998.tb00177.x

Rusbult, C. E., \& Van Lange, P. A. M. (2003). Interdependence, interaction, and relationships. Annual Review of Psychology, 54, 351-375. doi:10.1146/annurev.psych.54.101601.145059

Rusbult, C. E., Van Lange, P. A. M., Wildschut, T., Yovetich, N. A., \& Verette, J. (2000). Perceived superiority in close relationships: Why it exists and persists. Journal of Personality and Social Psychology, 79, 521-545. doi:10.1037/0022-3514.79.4.521

Schmitt, D. P. (2005). Is short-term mating the maladaptive result of insecure attachment? A test of competing evolutionary perspectives. Personality and Social Psychology Bulletin, 31, 747-768. doi:10.1177/ 0146167204271843

Sprecher, S. (1999). 'I love you more today than yesterday': Romantic partners' perceptions of changes in love and related affect over time. Journal of Personality and Social Psychology, 76, 46-53. doi:10.1037/ 0022-3514.76.1.46 
Stanley, S. M., \& Markman, H. J. (1992). Assessing commitment in personal relationships. Journal of Marriage and the Family, 54, 595608. doi:10.2307/353245

Van Lange, P. A. M., Rusbult, C. E., Drigotas, S. M., Arriaga, X. B., Witcher, B. S., \& Cox, C. L. (1997). Willingness to sacrifice in close relationships. Journal of Personality and Social Psychology, 72, 13731395. doi:10.1037/0022-3514.72.6.1373

Vrij, A., Floyd, M., \& Ennis, E. (2003). Telling lies to strangers or close friends: Its relationship with attachment style. In S. P. Shohov (Ed.), Advances in psychology research (pp. 61-73). Hauppauge, NY: Nova Science Publishers.
Wei, M., Russell, D. W., Mallinckrodt, B., \& Vogel, D. L. (2007). The Experiences in Close Relationship Scale (ECR)-Short Form: Reliability, validity, and factor structure. Journal of Personality Assessment, 88 , 187-204. doi:10.1080/00223890701268041

Received May 13, 2010

Revision received April 6, 2011

Accepted August 16, 2011

\section{Call for Nominations: Psychology and Decision Making}

The Publications and Communications (P\&C) Board of the American Psychological Association has opened nominations for the editorship of Psychology and Decision Making. The editorial search is co-chaired by Valerie Reyna, $\mathrm{PhD}$, and David Dunning, $\mathrm{PhD}$.

Psychology and Decision Making, to begin publishing in 2014, is a multidisciplinary research journal focused on understanding the psychological and cognitive processes involved in decision making. The journal will publish empirical research that advances knowledge and theory regarding all aspects of decision making processes. Specifically, the goal of the journal is to provide for an interdisciplinary discussion of contrasting perspectives on decision making.

Submissions from all domains of decision making research are encouraged, including (but not limited to) research in the areas of individual decision making, group decision making, management decision making, consumer behavior, reasoning, risk tasking behavior, risk management, clinical and medical decision making, organizational decision making, choice behavior, decision support systems, strategic decision making, interpersonal influence, persuasive communication, and attitude change.

Editorial candidates should be members of APA and should be available to start receiving manuscripts in January 2013 to prepare for issues published in 2014. Please note that the P\&C Board encourages participation by members of underrepresented groups in the publication process and would particularly welcome such nominees. Self-nominations are also encouraged.

Candidates should be nominated by accessing APA's EditorQuest site on the Web. Using your Web browser, go to http://editorquest.apa.org. On the Home menu on the left, find "Guests." Next, click on the link "Submit a Nomination," enter your nominee's information, and click "Submit."

Prepared statements of one page or less in support of a nominee can also be submitted by e-mail to Sarah Wiederkehr, P\&C Board Search Liaison, at swiederkehr@apa.org.

Deadline for accepting nominations is January 10, 2012, when reviews will begin. 